\title{
New technologies and the education of information professionals
}

\author{
Catherine Hare \\ University of Northumbria at Newcastle, UK
}

\section{Introducción}

In a recent article on the subject of distance learning at university level in the modern world of electronic networks, Sir John Daniel, Vice Chancellor of the UK's Open University began with the statement that "the world of the late 1990s is not the world of the late 1980s"[1]. You might say that it would be surprising if this were not the case but the changes have been especially great for the information professional. Key factors in this change have been

- the new status of information as an asset and resource for organisational development and competitive advantage;

- the development of the information and communication technologies, which has resulted in the exponential growth of information in electronic format and the emergence of the end-user culture, which potentially bypasses the information professional as intermediary;

- the shift from the focus on the teacher teaching to the learner learning, which heightens the importance of information resources and therefore impacts on the role of the information professional;

- widening of participation in higher education both for initial and lifelong learning, which requires flexible models of teaching and learning; and

- the globalisation of society which breaks down not only physical but also temporal barriers. A key characteristic of globalisation enables asynchronous exchanges anywhere and anytime.

Within this highly dynamic environment, information professionals not only feel the pull of the situation described above but also the push of their own professional aspirations. These aspirations are traditionally explained as getting the right information to the right person at the right time and at the right price. In this context information professionals need to be able to respond to the new challenges and therefore require professional education which gives them the knowledge and the skills they need.

To meet these needs the domain of information studies today has extended its scope to embrace not only the traditional sphere of published information associated with the library but also information generated by organisations as the outputs of their business activities. In the information services of organisations, as opposed to libraries, the emphasis shifts from collection development and availability of a resource base (usually purchased externally), to the active communication of a resource, both internally generated as well as externally acquired, to meet user need and aid decision-making. Nowadays, via web technology in particular, these types of information (i.e. internal reports, online databases) often merge and are communicated seamlessly for the PC user. New information specialisms such as records management, knowledge 
management, documentation control and web management are in some contexts being consolidated and in others being established to develop and control these new and highly dynamic environments.

Thus information professionals in training need not only to learn about and be able to use the new technologies as elements of the working world to day. They also need to understand them and the potential for their use so as to exploit them in fulfilling their professional role, because these new technologies are the technologies that are specific to information and communication. Additionally, considering information professionals as learners, these new technologies bring further opportunities to all students by providing a means of supporting learning at a distance where the separation between the teacher and the learner is as much temporal as physical. There remains however the unchanging goal of university education, which is the development of understanding that goes far beyond the transmission of information and the communication of knowledge. This "requires the student to engage actively with operational aspects of the subject matter and to articulate its theoretical aspects (author's italics)"'[2].

So there are the three facets of the information professional's life today that are changing in relation to new technologies.

1. the way in which business operates in general and the prominence that information is taking for business

2. the tools of the trade that information professionals use in their own work

3. the means by which they are able to update their skills both as part of initial training and also re-training

The aims of this paper will therefore be to present:

- the current state of education for information professionals in the United Kingdom

- interrelationship between the information and communication technologies and the subject matter of information studies

- the development of and the role of technology in an asynchronous system of learning for information professionals

- the case study of the Masters in Records Management by Distance Learning in the School of Information Studies at the University of Northumbria at Newcastle in the United Kingdom.

\section{EDUCATION FOR INFORMATION PROFESSIONALS}

In the UK information courses are delivered as undergraduate or postgraduate programmes by 18 university departments in both old and new universities i.e. the former polytechnics. In the past they were collectively known as the "library schools" but now only five maintain the word library in their title. In their individual institutions these schools may be found in faculties of humanities, social sciences, business, management and science [3] and may often have changed home as my own school has. We are currently based in the Faculty of Arts and Design but in previous incarnations have belonged to every faculty except the Faculty of Engineering, Science and Technology, although ironically our students are classified for funding purposes in the same category as computing students who are in this faculty.

Reflecting this diversity of affiliation, underpinned by the twin concepts of information and communication, awards and qualifications cover both the arts and sciences at undergraduate and postgraduate levels. The traditional combination in joint programmes of information studies with other academic subjects, especially from social sciences, is now being supplemented by courses that combine information and computer science as, 
for example, the Information and Computing degree at University College London. The recognition of the need for information professionals to be proficient in the use of IT has resulted in the inclusion of IT in all courses but in a way which requires learners to go beyond the acquisition of what are becoming generic information and technology skills.

We need however to remember that we are discussing here not just university level education in a particular subject area of information concepts. We are also concerned with professional education. This has an added target of preparation for professional practice which nowadays means achieving what Professor Micheline Beaulieu, Chair of Information Science and Head of Department of Information Studies at University of Sheffield (the premier department for research and postgraduate education in information studies in the UK), calls "professional recognition in the electronic information age" [4]. She believes that professional competencies extend beyond the definition of the level of technical competence and favours the set of eleven competencies developed by the Special Libraries Association in the United States [5]. These eleven competencies can be grouped into three categories:

1. technical competencies covering the use of appropriate information technology to acquire, organise and disseminate information, creating information products and the ability to identify and evaluate information sources

2. social competencies relating to provision of instruction and support for information users to meet their needs

3. organisational competencies in terms of specialised knowledge relevant to their employee, ability to develop, manage and information services and to undertake research into information management challenges and in general greater involvement in achieving the objectives of the organisation.

This wide range of areas of competence is found in most information studies programmes. Of particular note however is the approach to the teaching of information technology which needs to be studied not only as an end in itself but also as a means to an end and an agent of change in the whole information process from creation through storage to retrieval. As Beaulieu explains

"Information technology not only provides more sophisticated tools to carry out traditional tasks but the technological tools themselves alter the task and change the very nature of the intellectual operations" [6]

The student therefore needs to learn not only what the technology is, needs to be able to use it, but also needs to understand its strengths and weaknesses. S/he needs to study through the technology, as well as learn about the technology, but in a way when allows them to disentangle the principle from the practice, the knowledge from the skill. It requires "a holistic approach to learning...which incorporates hands on experience" [7]. Also the learning will not stop once formal studies are complete, because the technologies will continue to develop and impact on their work.

There is also the question of staff already working in the field who too will need continuing professional development in integrating the technologies into information management, but also in learning how to learn, so that they can continue to move on as their professional activity demands. As mentioned earlier, we are also seeing the emergence of new specialisms that sometimes develop in practice in the workplace before being consolidated in theory and being supported by professional education.

This has very much been the case of records management in the UK where, until very recently, there were no programmes aimed exclusively at providing a professional 
qualification for records managers who are responsible for managing, throughout its lifecycle, the information produced and received by their organisation in conducting its business activities.

In all fields, distance learning, as a means of both initial and continuing education, is very much the "height of fashion" [8]. The very effective and large scale operation of the British Open University has played a key role in showing what can be achieved through distance education, but this mode of study, to date, has only had a limited implementation in information studies in the UK. It however became clear to us that, if we wanted to provide professional education for records managers, a campus-based model was not appropriate, because all of the potential students were already working as records managers and could not be released to come and study full-time in Newcastle. Distance education was very new to our University and totally new to our School, but we had 50 years experience of educating information professionals. The decision was therefore taken and resulted in the launch of the Masters in Records Management by Distance Learning in 1996.

\section{MASTERS IN RECORDS MANAGEMENT BY DISTANCE LEARNING}

The course was designed, as indicated above, to meet the needs of people already working in records management and who needed to combine full-time work with their studies. This immediately takes us into the domain of distance learning, where the distinctive characteristic is the fact that the student is physically remote but that physical remoteness implies also a temporal difference between the teacher and the learner, unlike in classroom teaching. Some distance learning programmes do overcome the temporal difference by using such technologies as video conferencing or web based conferencing but in our scenario (i.e. campus-based tutors working standards hours and full-time workers) the synchronous solution was not possible. There was however the possibility of using the information and communication technologies which, as with other information professionals, is not only a topic of study, but also a means to an end and a key agent in the work they do.

To show how we implement ICTs in our course, I need to describe its structure further. The course is a three year course with the first two years covering the taught element and the third year being devoted to the masters dissertation. Each year begins with a compulsory residential school which allows the students to establish a rapport with their tutors and fellow students. In the first two years the students begin the study of the first unit of the year at the residential school.

Year One sets the foundation and comprises the following units:

- Interpersonal Skills for Records Management

- Records Management in the Organisation

- Strategic Approaches to Management for Records Management

- Introduction to Information Storage and Retrieval for Records Management (double unit)

- Lifecycle Approach to Records Management.

Year Two develops the theory and practice introduced in Year One, combined with preparation for the masters dissertation and covers: 
- Managing Active Records*

- Managing Non-Current Records*

- Archives Management*

- Records Management in the Electronic Environment* (double unit)

- Research Methods for Records Management.

The units are studied in sequence with a change after six weeks, or twelve weeks in the case of the double units. In order to recognise the learning the students, as experienced practitioners, have already achieved, a claim for Accreditation of Prior Experiential Learning (APEL) can be made for the units marked with an asterisk above.

Year 3 is devoted to the dissertation the proposal for which is completed as part of the assessment for the Research Methods for Records Management unit.

In addition to the specialist aspects of records management, the units of study include the social and organisational competencies mentioned above. The technical competencies do appear explicitly in certain units such as the sections on databases in Information Storage and Retrieval and on the information and communication technologies in Records Management in the Electronic Environment.

These sections however do not only explain about the technologies but also embed and integrate their study into the active learning of the students. This is achieved through the course materials which become the prime means of the students' learning in distance learning and the pedagogic model on which they are based.

In our case we adopted the model proposed by Professor Phil Race [9] (Race 1984), formerly Professor of Educational Development at the University of Glamorgan, who identifies the four stages that all students, whether campus-based or at a distance, need to experience as part of the learning process viz. wanting, doing, digesting and feedback. Looking at these processes in more detail we can say

1. The wanting is created by identifying learning outcomes and it is sustained through feedback. It is also influenced by the way in which the materials are designed; for example, in terms of how they look and how easy they are to read.

2. The doing is provided through a range of tasks in the form of activities, assignments or self assessment questions.

3. The feedback comes in the main from the responses to the self assessment questions, but also from the assignments where the tutor supplies the written feedback at a later stage.

4. The digesting is achieved by reviews and summaries.

Having established the pedagogic model there was then the issue of the delivery mode. The information and communication technologies which were to be part of the subject of study were available as a means of delivery. A pilot study [10] was undertaken which covered both paper-based and electronic materials and involved records managers working for a London-based data storage company. The outcomes of the study were a preference for practical activities, for a mixture of formats and feelings of isolation through lack of interaction. The decision was therefore taken to deliver the learning materials on paper which would incorporate self assessment activities with responses, but 
to use electronic communication systems such as electronic mail and computer conferencing for teacher to student and students to student discussions. One very major factor in this decision was also the considerable difference in time needed to develop the electronic materials compared to the paper materials. It required $70 \%$ more time, although this measure might vary depending on the software used.

For two years this was the model followed, although the computer conferencing activities had to be replaced by email after year one because of technical problems. In any six week period the student would complete activities independently, getting feedback from within the learning materials and also send emailed responses by a prescribed date to the relevant tutor with a copy to their fellow students. The tutor would then send a summary response to all the students as a group. The activities were not formally assessed which meant that not all of the students participated. The lack of conferencing software also meant that it was not possible to have a threaded discussions as would happen in a face-to-face classroom situation. Email was also used to send out marks to individual students with specific comments and a message presenting the overall performance of the group with general comments about the assignment as a whole. We gave considerable thought to using email,

particularly for the individual marks, as emails constitute records and had been studied as such. We were therefore careful to reinforce and confirm the mark by sending a handwritten and signed assessment feedback sheet.

\section{ELECTRONIC DELIVERY}

Towards the end of this initial period the University embarked upon an initiative to extend the use of ICTs in teaching and learning. One of the strands was to exploit expertise in distance learning within the university by offering funding to move to electronic delivery. Our School was one of seven projects funded. Our aims were twofold:

1. to convert two of the existing units from the Masters course

2. pilot a commercial electronic learning support system that was chosen because of the level of its penetration into the education market.

We selected the Records Management in the Electronic Environment unit for conversion to electronic form because of the potential to reinforce the study of the technological nature of the subject through electronic delivery and we chose the Research Methods unit because it is a core area on all programmes within the School. There was therefore the potential to use the new electronic materials developed not only for the distance learners but also for campus-based students, who could learn asynchronously. This is becoming more desirable as many students now have to work to support themselves through their studies and are not always available for timetabled slots and the ICTs equipment in the university is available, readily accessible and frequently underused outside of the normal working hours.

The first task was to test the pedagogic model in the new medium. The results were that it was deemed to be valid irrespective of medium. The next stages were to

- design a layout which was attractive and easy to use

- build in the navigational system using hypertext links

- develop a format for activities that could give immediate feedback

The sections on the information and communication technologies were tested by the Year 
2 students as part of the Records Management in the Electronic Environment unit. Each student completed a questionnaire and was interviewed by telephone. Their evaluation presented both points in favour and points against.

The points in favour were:

- "less cold than paper"

- "successful activities"

- "effective and good to learn from"

- "appropriate for studying subject matter"

- "very good for revision"

The points against included:

- "getting lost"

- technical problems e.g. installation

- "not conducive to deep thought"

- "other media would be nice"

For the other unit, video material was introduced, but this hugely increased the development time not least because all of the work, from setting up and recording the video clip to putting the material into the template and cutting the master disk, had to be done within the project. These materials are about to be piloted with the Year 3 students during the residential school.

As regards the electronic learning system, we have successfully installed and tested it for use on campus.

We have just received funding for the next stage of the ICTs project. The focus of this stage will be the delivery, totally by electronic means, of the learning for Year 2 students in Semester 2 of academic year 1999 to 2000. As part of the residential school in September 1999 they will be trained to use the learning system on campus. Once they have returned to their work base or home base, they will test the remote access facilities, so that, when they begin their studies in February 2000 the technical problems should be minimised.

In this stage, we shall for the first time have a robust system for threaded discussions and will be able to provide the students with an easily accessible chat room that will not be available to the tutors. Through the administrative system, we shall also be able to see when and how the students learn, and they will be able to manage their own learning in what we hope will be a more transparent way.

\section{LESSONS LEARNED}

The project is still ongoing, but it has been possible to draw conclusions on findings to date. The key outcome has been the recognition that you need three lots of time: 
1. to develop and design the pedagogical model

2. to write the materials

3. to produce the materials

This has consequences for the off-stated claim that ICT learning is more efficient in terms of teacher time and therefore potentially more cost effective. Another factor that has emerged is the way in which existing procedures and regulations, both within the university and in the organisations where the students are based, may need to change to accommodate the new learning mode. For example will the library send books to distance learning students and will organisations allow access through their firewalls? But it is not a question of totally changing from one system to a new one. The reality is that the environment for learning will be hybrid: it will comprise both traditional face-to-face and technology-based formats, just as the learning and other information resources are a mixture of paper and electronic resources. This hybrid mix of resources plays such a key role in learning for all, but especially for the information professionals who also need to use them as the raw materials and tools of their profession.

Electronic learning materials therefore have a major role to play in the education of information professionals. One of the students who took part in the evaluation said that it is "a great advantage to have electronic course materials". They can be very effective but it is important to make sure that the technology does not drive the development. It is the message that should be the prime focus not the medium. This means that there need to be a number of specialists involved in the process of learning materials development, from the person responsible for the content through the instructional designer to the technical producer.

This paper began with a quotation from the head of the British Open University and it is therefore appropriate to return to him for a clear summary of how best to exploit the new technologies for distance learning

"My conclusion is that, if you want to use hard technologies for university-level teaching and learning that is both intellectually powerful and competitively cost-effective, then you must concentrate on getting the soft technologies right." [11]

It is easy to understand what he means by the hard technologies but it is necessary to clarify what the soft technologies are. As he explains these are processes, approaches, conventions, modus operandi and ways of working together on specific projects, all of which are an integral part of how organisations operate today. These working practices, based on teamwork, have not been typical of the way universities have worked in the past, which have been very individualistic in academic work.

It would be incorrect to say that universities do not have processes. However these processes, such as

- registering of students outside the conventional induction period

- ensuring that the licence for use of electronic publications is not restricted to on campus access and from within a single country

- employing experts to provide the specialist input required

need to change. For it is only by changing these practices now and in the future that universities will be able to use the technologies effectively and efficiently. This is what we are trying to do within our project, which has the bonus of harnessing the technologies 
as well as studying the technologies in which our students will become experts.

\section{REFERENCES}

[1] Sir John Daniel, "Distance learning in the era of networks", ACU Bulletin of Current Documentation, 138, April 1999, p.7-9.

[2] ibid.

[3] M. Beaulieu, "Developing the information professional: whose responsibility? Educating and developing the information professional for success", Impact: Journal of the Career Development Group, 1(7), August 1998, p.107-112,.

[4] ibid.

[5] Special Libraries Association, "Competencies for special librarians of the 21st century", SLA, Washington D.C, 1996. (http://www.sla.org)

[6] M. Beaulieu, op.cit.

[7] ibid

[8] Sir John Daniel. Op. cit.

[9] P.Race, "Open Learning Handbook", 2nd ed., Kogan Page, 1984.

[10] J. McLeod, "Piloting a postgraduate distance learning course in Records Management for practising records managers", Records Management Journal, 5(2), 1995, p.61-78.

[11] Sir John Daniel, op. cit.

(C) Ediciones Universidad de Salamanca. 